\title{
A utopia do desenvolvimento sustentável
}

Igor Zanoni Constant Carneiro Leão*

RESUMO - Este texto mapeia brevemente o caminho percorrido nas últimas décadas sobre o conceito de desenvolvimento sustentável, indicando seu progressivo enriquecimento lado a lado com crescente imprecisão teórica. Para a construção mais sólida desse conceito, se propõe uma abertura de visão para áreas pouco vistas por ambientalistas, como a psicanálise e a filosofia oriental, entre outras.

Palavras-chave: Desenvolvimento sustentável. Ecologia. Modernidade.

O pensamento ambiental, desde seu início na segunda metade do século XX, mostra uma imbricação entre temas e propostas nas áreas da ecologia, economia, política e sociologia. Ao mesmo tempo ele é profundamente diversificado, apontando para mudanças econômicas e sociais com matizes muito diferentes, de tal forma que é possível perguntar se o seu conceitochave, o desenvolvimento sustentável, pode ser construído de uma forma que não seja apenas utópica, e se é possível realmente intervir nos pontos principais sobre os quais o pensamento ambiental se debruçou, muitas vezes de forma bastante radical.

Procuremos em princípio situar o que queremos dizer. Vamos nos reportar ao texto da Comissão Mundial sobre o Meio Ambiente e o Desenvolvimento, publicado em 1987, síntese de um conjunto amplo de discussões sobre estes dois temas, e que é um dos textos fundadores do movimento ecológico moderno.

Já no seu primeiro capítulo, o texto alerta para o consumo excessivo de recursos da terra comprometendo o consumo das gerações futuras. Mais do que isso, esse consumo é desequilibrado entre as comunidades humanas, com cada país lutando pela prosperidade ou sobrevivência sem considerar o impacto que causa sobre os demais. Embora tenha havido progressos em várias partes do mundo, do ponto de vista da fome e da miséria, por exemplo, com frequência a prosperidade conseguida em algumas partes do mundo é precária, pois foi obtida mediante práticas agrícolas, como a monocultura, o desvio de cursos de águas, entre outras, que só trazem lucro e progresso em curto prazo. Hoje, a intervenção na natureza é crescente e os efeitos físicos das decisões econômicas atingem todo o globo. Assim, há uma interação profunda entre economia e ecologia ameaçando a base do progresso humano.

\footnotetext{
* Doutor em economia pela Universidade Estadual de Campinas. É professor do Departamento de Economia da Universidade Federal do Paraná. Endereço eletrônico: igorzaleao@yahoo.com.br.
} 
Essa interação envolve aspectos como: 1) Os desgastes do meio ambiente estão interligados. Assim, o desflorestamento, por exemplo, pode acelerar a erosão do solo e a formação de depósitos sedimentares em rios e lagos, a poluição do ar e a acidificação contribuem para matar florestas e lagos, indicando que é preciso tentar resolver vários problemas ao mesmo tempo; 2) Os desgastes ambientais e os padrões de desenvolvimento econômico se interligam. Por exemplo, as políticas energéticas estão ligadas ao efeito estufa global, à acidificação e ao desflorestamento, que ameaçam o desenvolvimento econômico, indicando que a economia não pode ser apenas a produção de riqueza e que a ecologia também não pode ser apenas a proteção da natureza; 3) Os problemas ambientais e econômicos ligam-se a vários fatores sociais e políticos. Assim, um crescimento populacional derivou de fatores como o status das mulheres, seu direito de autodeterminação na sociedade e outros valores culturais. Por outro lado, o desgaste do meio ambiente e o desenvolvimento desigual podem causar agudas tensões políticas e sociais; 4) As características sistêmicas do desenvolvimento fizeram com que se apagassem as tradicionais distinções entre assuntos de significação local, nacional e internacional. Os ecossistemas não respeitam fronteiras nacionais, a poluição do ar se espalha por áreas muito vastas, $\mathrm{O}$ efeito estufa compromete a vida em toda a Terra e assim por diante.

Diante dessas conexões, o relatório propõe o conceito de desenvolvimento sustentável, que fornece uma estrutura para integração de políticas ambientais e estratégias de desenvolvimento em seu sentido mais amplo. A busca desse conceito exige mudanças nas políticas internas e internacionais de todas as nações. Ele pode ser definido como o desenvolvimento que procura atender as necessidades e aspirações do presente sem comprometer a possibilidade de atendê-las no futuro. Ao mesmo tempo, ele só pode ser buscado através da inauguração de uma nova era de cooperação internacional baseada na premissa de que todo ser humano - os que já existem e os que virão - tem direito a uma vida razoável.

Durante todo o relatório as implicações do desenvolvimento sustentável são buscadas enfatizando alguns dos principais objetivos das políticas ambientais e desenvolvimentistas decorrentes, como retomar o crescimento, alterar a qualidade do desenvolvimento, atender às necessidades essenciais de emprego, alimentação, energia, água e saneamento, manter um nível populacional sustentável, conservar e melhorar a base de recursos, reorientar a tecnologia e administrar o risco, incluir o meio ambiente e a economia no processo de tomada de decisões.

Dessa forma, a Comissão concentrou sua atenção nas áreas de população, segurança alimentar, extinção de espécies e esgotamento de recursos genéticos, indústria e assentamentos humanos, entendendo que todas se interligam e não podem ser tratadas isoladamente.

A presidência da Comissão foi exercida por Gro Harlem Brundtland, primeira-minis- 
tra da Noruega, país onde se congregou a Comissão que passou a exercer importante trabalho relacionado com o meio ambiente global. O período em que essa Comissão esteve reunida foi marcado por duas crises, em 1973 e 1979, da questão energética vinculada ao petróleo à crise econômica que se abre com o fim de Bretton Woods e com a ascensão neoliberal nos Estados Unidos e Inglaterra, notadamente, como presidente Ronald Reagan e a primeira-ministra Margareth Thatcher, e uma longa crise da dívida externa nos países do terceiro mundo. Ao mesmo tempo, as questões ambientais ganhavam importância e ressonância com críticas de autores importantes aos efeitos nocivos da tecnologia moderna sobre o meio ambiente e a qualidade da vida humana, bem como sobre o efeito do uso excessivo de hidrocarbonetos na matriz energética, somando-se às críticas já antigas aos perigos da energia nuclear usada como uma das principais fontes de energia em vários países desenvolvidos.

Nesse sentido, a Comissão não podia deixar de pensar o desenvolvimento a partir dos problemas dessa época tão difícil. Em um texto de 2007, Gro Harlem Brundtland volta ao documento Nosso Futuro Comum, lembrando que no ano em que este foi escrito os efeitos das mudanças climáticas ainda não estavam tão evidentes, mas o relatório já trazia um apelo para que o crescimento econômico futuro não representasse o esgotamento dos recursos naturais, o comprometimento do meio ambiente e um fosso ainda maior entre ricos e pobres.

Para ela, a questão ambiental e a necessária cooperação internacional são fundamentais para um novo consenso de segurança, que exige, para se encontrar paz global, direitos humanos, desenvolvimento sustentável e redução das distâncias entre ricos e pobres. O vínculo estreito entre a segurança mundial e a sustentabilidade fez com que o prêmio Nobel da Paz tenha sido entregue, nos últimos anos, a pessoas que se destacaram na luta contra a pobreza e em prol do meio ambiente, como o ativista ecológico Al Gore, ex-vice presidente dos Estados Unidos, o Painel Intergovernamental sobre Mudanças Climáticas (IPCC), Muhammad Yunus, que criou o chamado Banco dos Pobres em Bangladesh, a queniana Wangari Maathai, que mobilizou as mulheres para promover o desenvolvimento sustentável na África e a advogada Shirin Ebadi, defensora dos direitos humanos de mulheres e crianças no Irã.

A preocupação com o desenvolvimento sustentável levou Gro a uma campanha contra o tabaco que deu origem ao primeiro tratado sobre saúde global, bem como a mesma preocupação levou cientistas, governos e autoridades públicas de saúde a um trabalho conjunto frente à ameaça da SARS (síndrome aguda respiratória asiática ou pneumonia asiática). Houve uma resposta semelhante quando a gripe aviária tornou-se uma questão de saúde mundial.

Fica claro, assim, que questões como a AIDS, a pobreza e as ameaças ambientais têm sido enfocadas de maneira conjunta com outras questões fundamentais ligadas aos direitos 
humanos, como o terrorismo e a proliferação nuclear, exigindo uma maior colaboração entre países ricos e pobres. Ao mesmo tempo, essa colaboração exige que os países industrializados assumam responsabilidades na redução de emissões que intensificam o efeito estufa, bem como que se caminhe rumo a uma economia verde, diminuindo drasticamente a pegada ambiental do carbono e trazendo um ganho de eficiência à indústria do petróleo.

Essas observações indicam que o conceito de desenvolvimento sustentável tem se alargado desde a década de 80 até a atualidade, envolvendo problemas que não estavam claros no seu escopo inicial. Entretanto, quando caminhamos em uma biblioteca, pelas prateleiras sobre sustentabilidade, notamos que esse conceito tem se estendido ainda mais do que o exposto acima pode indicar.

Tomando agora os textos de Enrique Leff, um autor recente com grande volume de produção em pensamento ambiental, vemos como se complexificam as observações acima. Assim, ele discute possibilidades de calcular um valor real da natureza na economia e é contra a pretensão de reduzir os diversos valores do ambiente a uma unidade homogênea de medida. Isto porque a valorização dos recursos naturais está sujeita a temporalidades ecológicas de regeneração e produtividade que não correspondem aos ciclos econômicos, bem como porque os valores e interesses sociais que definem o significado cultural, as formas de acesso e os ritmos de tração e transformação dos recursos naturais, constituem processos simbólicos e sociais de caráter extraeconômico não redutíveis a preços de mercado.

Assim, as lutas sociais para melhorar as condições de sustentabilidade e a qualidade de vida estão inseridas em uma reapropriação social da natureza. $O$ autor pensa não apenas na compatibilização entre conservação e desenvolvimento através da internalização de condições ecológicas para um crescimento sustentável da economia, mas também o ambiente como potencial para um novo paradigma produtivo que integre a natureza e a cultura como forças produtivas.

Dessa forma, as condições ecológicas e comunais da produção são o suporte de uma nova racionalidade produtiva, entrelaçando processos de ordem natural, cultural e tecnológica e fundando a sustentabilidade em princípios de equidade, diversidade e democracia, ao invés da simples economia verde através do cálculo dos custos da preservação e da restauração ambiental. O que o ambientalismo propõe é outra racionalidade produtiva baseada nos potenciais da natureza e da cultura.

Nesse sentido, os movimentos de resistência ambientais, além de distinguirem-se por seus objetivos de valores materialistas dos mais ricos, propõem projetos produtivos e sociais alternativos, onde toda a luta pela equidade e pela justiça se trava a partir de princípios de di- 
versidade e diferença, de identidade e autonomia, e não de transações e compensações estabelecidas com regras de valorização, negociação e outras no âmbito da racionalidade econômica. As categorias de impacto, custo, dívida e distribuição ecológica, dominantes no discurso atual de muitos ambientalistas, devem ser substituídas pelo discurso da apropriação da natureza pela autogestão da produção, pela diversidade cultural e pelas identidades étnicas.

O autor propõe uma ecologia política, onde os atores mais novos são movimentos sociais que articulam a defesa do ambiente e dos recursos com suas lutas pela democracia, autonomia e autogestão. $\mathrm{O}$ ambientalismo se define, portanto, por princípios de equidade, sustentabilidade, diversidade, autogestão e democracia. Seus atores sociais são como unidades indígenas e camponeses, populações urbanas e outras, que pensam o acesso e a apropriação da natureza através de novas estratégias de poder, valores culturais e práticas de produção alternativas. As condições de produção e os estilos de vida dos povos são questionados.

A questão principal de quem possui a natureza deve ser respondida pela mobilização dos povos que transformam as relações de poder para redistribuir os custos ecológicos, reapropriar-se dos potenciais da natureza, fundar novos paradigmas de desenvolvimento e construir novas utopias. Pensa-se, portanto, em novos direitos humanos, novos direitos culturais, em exigências tradicionais na esfera econômica, como melhor distribuição da riqueza, ou na esfera política e cultural, mas também na rejeição de políticas econômicas que geram exploração econômica, marginalização política, segregação cultural e degradação da natureza. Finalmente:

\footnotetext{
Nesta perspectiva, o desenvolvimento sustentável vai além do propósito de capitalizar a natureza e de "ecologizar" a ordem econômica. A sustentabilidade ambiental implica um processo de socialização da natureza e o manejo comunitário dos recursos, fundados em princípios de diversidade ecológica e cultural. Neste sentido, a democracia e a equidade se redefinem em termos dos direitos de propriedade e de acesso aos recursos, das condições de reapropriação do ambiente. (LEFF, 2009, p. 42).
}

Este autor compõe com outros uma visão do desenvolvimento sustentável que fere a própria legitimidade das relações políticas e econômicas que subordinam povos indígenas e transtornam sua cultura. Mais do que isso, questiona a própria legitimidade do capitalismo como modo de apropriação da natureza, inclusive da própria natureza humana. O que está em jogo é toda a cultura contemporânea, e o ambientalismo é pensado de muitos pontos de vista que nascem na transformação humana do ambiente mas desembocam em todas as características da economia, da técnica e das características culturais das sociedades e do homem pós-moderno.

Se é assim, podemos pensar em uma nova cultura como proposta para esses problemas. Podemos pensar na contribuição para o ambientalismo do pensamento oriental e da 
psicanálise na proposta de uma nova ética humana e ambiental. Assim, podemos discutir a contribuição para a educação infantil do livro de Bruno Bettelheim, Uma vida para seu filho, lançado no Brasil pela Campus em 1987, e que se tornou uma referência para o estudo das primeiras relações entre pais que querem ser suficientemente bons no desenvolvimento da personalidade de seus filhos em seus primeiros anos de vida. A passagem consta de dois parágrafos a seguir transcritos, tratando da formação do superego em sua relação com a cultura cujo cerne é visto como a noção de bem e mal.

Enquanto observamos o progresso da atividade agressiva em nosso filho, podemos gradualmente discernir um progresso do desenvolvimento da brincadeira livre, que permite a expressão e satisfação do id (o tiroteio não estruturado em que vale tudo, no qual a agressividade é livremente descarregada), para um jogo mais estruturado em que está não a mera descarga de agressividade, mas uma integração maior - a ascendência do bem sobre o mal - é o objetivo. Assim, nós destruímos eles, os gregos derrotam os patifes troianos, os cavaleiros cristãos destroem os infiéis, os policiais encurralam os ladrões, os cowboys esmagam os índios selvagens. Como adultos objetivos, devemos saber que a cultura troiana era talvez superior à dos gregos da idade do bronze, ou que a causa dos índios era pelo menos tão boa quanto a dos cowboys. Mas essa objetividade é o produto final de uma luta moral e intelectual prolongada, um longo processo de depuração, moderação e refinamento das emoções. Para a criança, essa objetividade não pode ser fácil ou rapidamente alcançada, porque as emoções, e não o intelecto, estão no controle durante os primeiros anos. Nossas crianças querem acreditar que o bem vence, e precisam acreditar, para seu própro bem-estar, de forma a se tornarem pessoas boas. Repetir o conflito eterno entre o bem e o mal numa forma primitiva, compreensível para elas, e ver que o bem triunfa sobre o mal, serve à humanidade em desenvolvimento. (BETTELHEIM, 1987, p. 242).

Esta passagem me parece problemática por vários motivos. Em primeiro lugar, pelos exemplos históricos escolhidos. Houve para Homero na Ilíada a percepção de que os gregos foram moralmente superiores aos troianos e por isso puderam destruir Tróia? A causa dos índios foi depreciada em um processo de conquista cruel de seu território, que dizimou populações inferiorizadas, em termos tecnológicos, para a guerra. Como sabemos, Custer foi o "pequeno grande homem". Os cavaleiros cristãos moveram um genocídio durante as Cruzadas, como mostram os livros de história. É possível que o conceito de bem venha desses erros crassos de avaliação? Eles fazem parte de uma ideologia ocidental da história, que continua nos filmes violentos americanos, ou nos filmes em que só os americanos conseguem deter com heroísmo inaudito as forças irracionais do mal. Essa ideologia continua sendo passada para adolescentes e jovens, de modo que é difícil ver quando poderão ser reelaboradas, ou, quando o forem, se subsiste algo além de decepção com tudo que acreditaram. Penso que as ideias de bem e mal 
podem ser explicadas de outra forma, através dos mass media e dos bancos escolares. A história dos índios pode ser recolocada, a das Cruzadas e muitas outras também, não criando nas crianças um jogo de contraste entre preto e preto, mas fazendo descobrir que a vida é colorida, podendo ser vista através das contas de vidro que escolhemos, para lembrar O Jogo das Contas de Vidro, de Hermann Hesse.

Essa é uma prerrogativa humana desde a infância: escolher seus valores morais e pessoais. É claro que a ideologia do poder do Império deseja uniformidade, e esta começa com a formação de um superego cruel. Mas é necessário domar assim os instintos do id? E realmente são domados ou exponenciados? Como apontou em palestra recente o Lama Padma Samten, em Curitiba, confunde-se aqui uma cultura, a nossa cultura dominante nos últimos séculos, com o ideal de civilização e com o superego bem estruturado e funcional. Sempre foi assim? É assim que os indígenas socializam seus filhos, ou que as epopeias indianas retratam a difícil luta entre bem e mal?

Por outro lado, não precisamos assentar nossa cultura em enganosas ideias e ideais de bem e mal. Podemos assentá-la, por exemplo, na ideia budista de impermanência, na qual todas as nossas escolhas pessoais, por melhores que sejam, estão fadadas a desaparecer. Mesmo o maior amor não dura, no limite porque um dos parceiros vai morrer um dia, e depois o outro. Outra ideia importante é que tudo que vivemos são construções que levam a uma vida insatisfatória, conflitiva, no samsara, quando repetimos ciclicamente experiências que levam ao sofrimento. Esse sofrimento só pode ter fim saindo do samsara, e do ciclo de nascimento e morte, o que pressupõe liberdade diante das escolhas feitas, e a mudança de personagens assumidos em termos de compaixão, amor, alegria, paz, paciência, esforço constante, concentração e sabedoria. Isso pode ser levado às crianças desde seus primeiros anos. O Tibet viveu longos séculos isolados do mundo cultivando uma cultura própria de paz e responsabilidade comum, fortalecida pelo budismo mahayana. A nossa vida é um teatro, mas podemos deixar de atuar e sair do palco, para a vida mais plena e mais real, de toda forma mais íntima e condizente com uma natureza humana que pode ser despertada. Aí não há essa dualidade entre bem e mal, a ideia de pecado se perde em prol de uma liberdade que conduz a um centramento em relações marcadas por valores, pela compaixão, a possibilidade de ver o outro em sua própria liberdade.

Nossa cultura está findando num caos econômico, social, ecológico. Todas as tentativas para salvá-la dependem de um ciclo de dependência e de aumento do grau de destruição da memória genética e cultural dos seres vivos. É hora de ultrapassar essa cultura.

Portanto, o pensamento ambiental em sua diversidade pode atingir uma radicalidade impensável quando de seu nascimento, trazendo para discussão discursos de muitas áreas além 
de meramente a economia, a sociologia e a ecologia, bem como pode discutir problemas essenciais hoje, como a violência e o mal-estar que permeiam as sociedades atuais, notadamente as do terceiro mundo.

\section{REFERÊNCIAS}

BETTELHEIM, B. Uma vida para seu filho. Rio de Janeiro: Campus, 1987.

Comissão Mundial sobre o Meio Ambiente e Desenvolvimento. Nosso futuro comum. 2. ed. Rio de Janeiro: Fundação Getúlio Vargas, 1991.

SACHS, I.; VIEIRA, P. F. (Org.). Rumo à ecossocioeconomia - teoria e prática do desenvolvimento. São Paulo: Cortez, 2006.

GORE, A. A Terra em balanço. São Paulo: Augustus, 1993.

VEIGA, J. E.; ZATZ, L. Desenvolvimento sustentável, que bicho é esse? Campinas: Autores Associados, 2008.

LOVELOCK, J. Gaia: alerta final. Rio de Janeiro: Intrínseca, 2010.

LOVELOCK, J. A vingança de Gaia. Rio de Janeiro: Intrínseca, 2006.

KLINK, C. (Org.). Quanto mais quente melhor? Desafiando a sociedade civil a entender as mudanças climáticas. São Paulo: Peirópolis, 2007.

SINGER, P. Ética prática. São Paulo: Martins Fontes, 1993.

LEFF, E. Saber ambiental. Petrópolis: Vozes, 2009.

LEFF, E. Epistemologia ambiental. São Paulo: Cortez, 2007.

LAMA Padma Samten. Disponível em: <http://www.caminhodomeio.org>. Acesso em: 2/2011. 